\title{
RANCANG BANGUN SISTEM INFORMASI E-LEARNING PADA SMK PGRI 37 JAKARTA
}

\author{
Evy Priyanti ${ }^{1}$, Rahmad Budi Ansyah² ${ }^{2}$ Fachrul Ramadhani ${ }^{3}$, Huzaiful Yaman ${ }^{4}$ \\ ${ }^{1}$ Program Studi Sistem Informasi Akuntansi \\ Fakultas Teknik dan Informatika \\ Universitas Bina Sarana Informatika (UBSI) \\ Jl. Kamal Raya No 18 Ringroad Barat, Cengkareng, Jakarta Barat \\ evy.evp@bsi.ac.id
}

2,3,4Program Studi Sistem Informasi

Fakultas Teknik dan Informatika

Universitas Bina Sarana Informatika (UBSI)

Jl. Kamal Raya No 18 Ringroad Barat, Cengkareng, Jakarta Barat

2budiansyahrahmad@gmail.com, 3Fachrulr0202@bsi.ac.id, 4Huzaifulyaman20@gmail.com

\begin{abstract}
ABSTRAK
Berdasarkan Permendikbud Nomor 60 Tahun 2014 menyatakan bahwa pelaksanaan PRAKERIN menggunakan sistem blok dilakukan selama setengah semester sekitar 3 Bulan, dengan waktu yang sangat banyak ini membuat siswa kekurangan dalam proses belajar mengajar dikelas. Oleh karena itu sangatlah dibutuhkan metode yang dapat menunjang sistem pendidikan yang dapat memudahkan siswa dalam belajar, salah satunya dengan sistem e-learning. Sistem ini dapat membantu siswa dalam belajar dan juga sangat membantu dewan pengajar dalam mengembangkan materi karena metode e-learning dapat dibuka dengan waktu yang lebih leluasa. Beberapa mata pelajaran dapat dibuatkan sistem e-learning supaya siswa lebih banyak waktu untuk belajar dan mengembangkan keilmuan yang mereka miliki. E-learning pada SMK PGRI 37 Jakarta membuat siswa semakin berkembang dalam mempelajari pelajaran-pelajaran yang tidak dapat dipelajari dikelas dikarenakan keterbatasan waktu yang disediakan. Sistem elearning dapat dikembangkan dengan maksimal sesuai dengan perkembangan jaman dikarenakan kecanggihan teknologi yang dapat memudahkan pekerjaan manusia saat ini. Elearning pada SMK PGRI 37 Jakarta adalah salah satu terobosan yang memanfaatkan teknologi guna perkembangan kemampuan dan perkembangan siswa.
\end{abstract}

Kata Kunci : E-learning, Sistem, Siswa

\begin{abstract}
Based on Permendikbud No. 60 of 2014 states that the implementation of PRAKERIN using a block system is carried out for half a semester around 3 months, with this enormous amount of time making students lacking in teaching and learning in class. Therefore it is very necessary methods that can support the education system that can facilitate students in learning, one of them with e-learning systems. This system can help students in learning and also greatly help the teaching board in developing material because e-learning methods can be opened with more free time. Some subjects can be made e-learning systems so that students have more time to learn and develop the knowledge they have. E-learning at SMK PGRI 37 Jakarta makes students progress in learning lessons that cannot be learned in class because of the limited time available. E-learning systems can be developed to the maximum in accordance with the changing times due to the sophistication of technology that can facilitate human work at this time. E-learning at SMK PGRI 37 Jakarta is one of the breakthroughs that utilizes technology for the development of students' abilities and development.
\end{abstract}

Keyword : E-learning, System, Student

Diterima Februari 8, 2020; Revisi Februari 11, 2020; Disetujui Maret 01, 2020 


\section{Pendahuluan}

Standar kompetensi dunia semakin meningkat, oleh karena itu peningkatan sumber daya manusia merupakan tuntutan yang harus dipenuhi oleh instansi pendidikan. Berbagai macam cara dan metode-metode pembelajaran telah diupayakan, agar siswa dapat menerima materi pelajaran dengan baik.

Pengaruh teknologi informasi dan komunikasi dalam dunia pendidikan semakin terasa sejalan dengan adanya pergeseran pola pembelajaran dari tatap muka yang konvensional ke arah pendidikan yang lebih terbuka dan bermedia. Dengan masuknya pengaruh globalisasi, pendidikan masa mendatang akan lebih bersifat terbuka dan dua arah, beragam, multidisipliner, serta terkait pada produktifitas kerja dan kompetitif

Perkembangan teknologi informasi tersebut, telah memberikan dampak yang cukup besar dalam dunia pendidikan. Internet yang dapat digunakan sarana belajar telah melahirkan konsep e-learning. E-learning dapat digunakan dalam pendidikan jarak jauh atau pendidikan konvensional tergantung dari kepentingannya. Konsep e-learning telah banyak digunakan diberbagai kalangan, mulai dari tingkat sekolah dasar sampai ke perguruan tinggi.

Mengembangkan model e-learning tidak sekedar menyajikan materi pelajaran ke dalam internet tetapi perlu dipertimbangkan secara logis dan memegang prinsip pembelajaran. Begitu pula desain pengembangan yang sederhana, personal, cepat, serta terdapat evaluasi online. Evaluasi atau ujian online membantu peserta didik agar tidak kewalahan dalam mengerjakan soal. Pertanyaan- pertanyaan yang menggunakan gambar atau tidak dapat terlihat dengan jelas. Setelah pelaksanaan evaluasi atau ujian. Guru tidak lagi kewalahan dalam membuat laporan nilai.

PRAKERIN (Praktek Kerja Industri) adalah kegiatan pendidikan, pelatihan dan pembelajaran yang dilaksanakan di Dunia Usaha Atau Dunia Industri dalam upaya pendekatan ataupun untuk meningkatkan mutu siswa - siswi Sekolah Menengah Kejuruan (SMK) dengan kompetensi (kemampuan) siswa sesuai bidangnya dan juga menambah bekal untuk masa - masa mendatang guna memasuki dunia kerja yang semakin banyak serta ketat dalam persaingannya seperti di masa sekarang ini.

Berdasarkan Permendikbud Nomor 60 Tahun 2014 menyatakan bahwa pelaksanaan PRAKERIN menggunakan sistem blok dilakukan selama setengah semester (sekitar 3 Bulan), dengan waktu yang sangat banyak ini membuat siswa kekurangan dalam proses belajar mengajar dikelas. Dengan berkurangnya proses belajar mengajar ini membuat para siswa kewalahan dalam mengejar Materi Pembelajaran yang telah diatur dalam kurikulum. Untuk mengejar Materi tersebut maka pengguna dari e-learning sekolah ini di khususkan bagi para siswa siswi kelas XI SMK PGRI 37 Jakarta dan semua mata pelajaran yang diajarkan pada semester tersebut

\section{Metode Penelitian}

Penelitian kali ini menggunakan metode kualitatif dimana penelitian berfokus pada fenomena yang diamati di SMKPGRI 37 Jakarta dimana kebutuhan siswa dan guru merupakan gambaran utama dalam penelitian. Dimana desain penelitiannya adalah semua proses yang diperlukan dalam perencanaan dan pelaksanaan penelitian pada SMK PGRI 37 Jakarta, yang membantu penelitian dalam pengumpulan dan menganalisis data dan dalam penelitian ini penulis menggunakan metode penelitian deskriptif dengan dua metode yaitu: metode pengumpulan data dan metode pengembangan perangkat lunak.

Metode deskriptif merupakan sebuah metode dalam penelitian dalam status kelompok manusia, suatu objek, suatu set kondisi, suatu sistem pemikiran, ataupun suatu kelas peristiwa pada masa sekarang. Penelitian deskriptif mempelajari masalahmasalah dalam masyarakat, serta tatacara yang berlaku dalam masyarakat serta situasisituasi tertentu, termasuk tentang hubungan, kegiatan-kegiatan, sikap-sikap, pandanganpandangan serta proses-proses yang sedang berlangsung dan pengaruh-pengaruh dari suatu fenomena.

Metode pengembangan perangkat lunak yang digunakan terdiri dari Use Case Diagram, Activity Diagram dan Class Diagram.

Use Case diagram adalah sebuah cara untuk mewakili cara sebuah sistem berinteraksi dengan lingkunganya. Use case mengilustrasikan aktifitas yang dilakukan user dengan sistem. Use case diagram dianggap sebagai pandangan eksternal atau fungsional dalam proses bisnis bahwa hal itu menunjukkan bagaimana pengguna melihat prosesnya, bukan mekanisme internal dimana proses dan sistem pendukung beroperasi.Sama seperti activity diagram, use case dapat mendokumentasi sistem yang 
sedang berjalan atau sistem baru yang sedang dalam proses pengembangan. (Dennis, 2015:120)

Activity diagram digunakan untuk menggambarkan aktifitas yang terjadi didalam sebuah proses bisnis. Activity diagram dapat digunakan untuk menggambarkan workflow(alur kerja) yang terdapat dalam use case,hingga rincian spesifik dari use case. (Dennis, 2015:130).

Menurut Sutanta dalam Irfiani \& Fintri (2013), "Entity Ralationship diagram merupakan suatu model data yang dikembangkan berdasarkan obyek-obyek dasar yang mempunyai hubungan atau kerelasian antar obyek-obyek dasar dengan menggunakan simbol-simbol grafis tertentu". Komponen - komponen dari ERD yaitu :

\section{a. Entitas (Entity)}

Entitas menunjukan objek-objek dasar yang terkait didalam sistem. Sesuatu yang digunakan untuk tempat penyimpanan data bisanya data tersebut berupa orang, tempat, objek, kejadian atau konsep. Untuk mengambarkan entitas dilakukan dengan mengikuti aturan sebagai berikut.

\section{b. Atribut (Attribute)}

Atribut merupakan karakteristik dari entity atau relationship, yang menyediakan penjelasan detail tentang entity atau relationship tersebut. Untuk menggambarkan atribut hal yang perlu dilakukan dengan mengikuti aturan sebagai berikut.

\section{c. Relasi}

Asosisai hubungan antar entitas, entitas yang berhungan dengan relasi diseut participant. Suatu hubungan yang terjadi antar sat atau lebih suatu entity.

Class Model atau Class Diagram Merupakan hubungan antar kelas dan penjelasan detail tiap-tiap kelas di dalam model desain dari suatu sistem, juga memperlihatkan aturanaturan dan tanggung jawab entitas yang menentukan perilaku sistem. Class Diagram juga menunjukkan atribut-atribut dan operasioperasi dari sebuah kelas dan constraint yang berhubungan dengan objek yang dikoneksikan. Class Diagram secara khas meliputi : Kelas (Class), Relasi Assosiations, Generalitation dan Aggregation, attribut (Attributes), operasi (operation/method) dan visibility, tingkat akses objek eksternal kepada suatu operasi atau atribut. Hubungan antar kelas mempunyai keterangan yang disebut denganMultiplicity atau Cardinality
Menurut Frieyadi dalam (Pratmanto et al., 2017) "LRS merupakan hasil dari pemodelan Entity Relational Ship (ER) beserta atributnya sehingga bisa terlihat hubunganhubungan antar entitas".

Berikut adalah Rancangan ERD dari system e-learning:

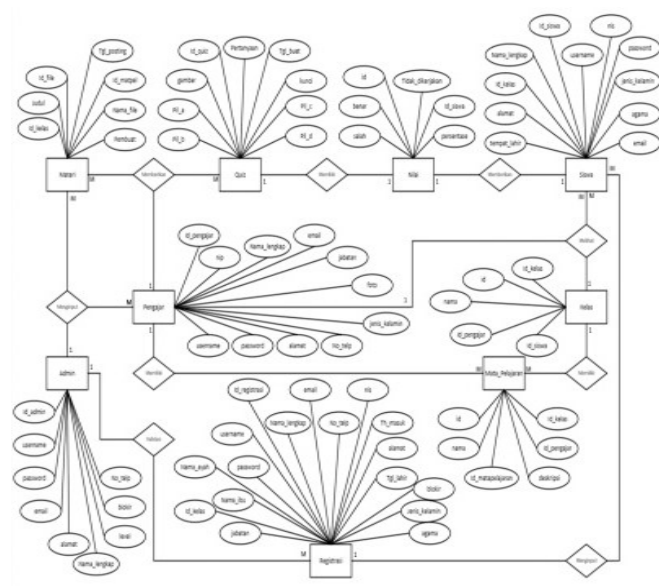

Gambar 3.1 ERD Sistem E-learning

Pada Gambar 3.1 dijelaskan berapa banyak atribut yang saling berinteraksi.

Berikut adalah class diagram e-learning:

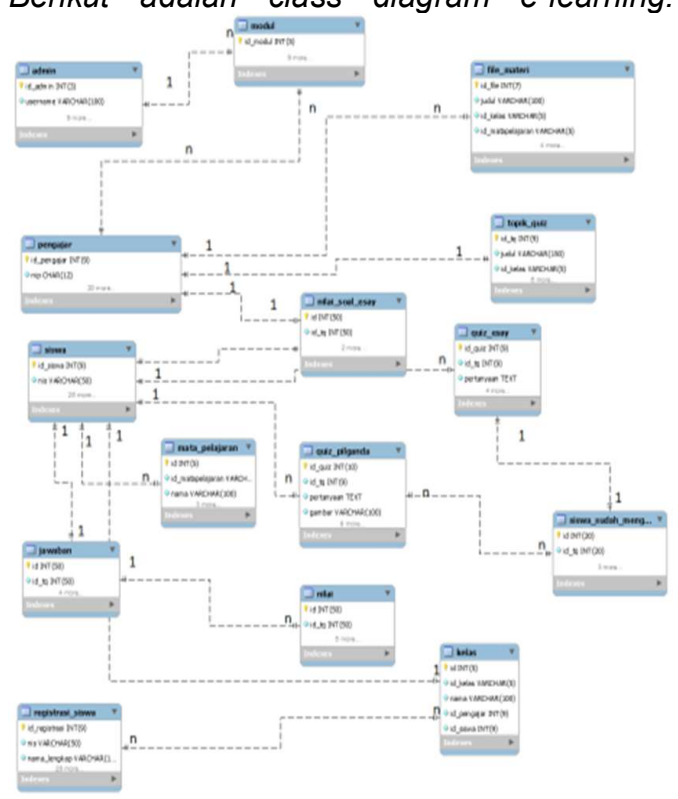

Gambar 3.2 Class Diagram

Pada Gambar 3.2 Digambarkan Class Diagram pada e-learning SMK PGRI 37 Jakarta.

\section{Hasil dan Pembahasan}




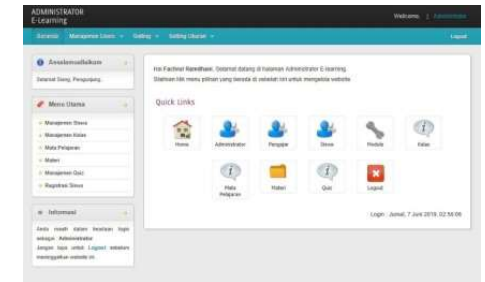

Gambar 3.3 Tampilan form admin

Pada Gambar 3.3 akan ditampilkan menu yang ada di form admin.

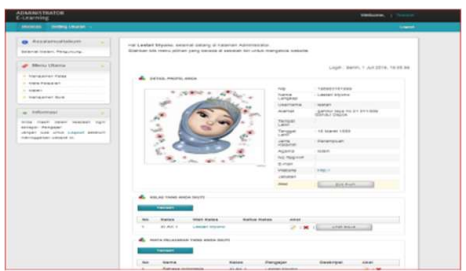

Gambar 3.4 Tampilan halaman Pengajar

Pada gambar 3.4 menampilkan halaman setiap guru atau pengajar

\section{Kesimpulan dan Saran}

Berikut kesimpulan yang didapat dari hasil penelitian ini:

Metode Pembelajaran dengan e-learning sebagai metode pembelajaran pendamping metode konvensional perlu diterapkan di SMK PGRI 37 Jakarta, Penggunakan aplikasi elearning ini maka proses belajar dan mengajar bisa di lakukan secara online (Intranet) dan tidak mengganti proses belajar dan mengajar secara penuh, melainkan hanya sebagai pelengkap dari sistem belajar yang sudah berjalan, aplikasi e-Learning dapat membantu proses pembelajaran di SMK PGRI 37 Jakarta secara maksimal.

Berikut saran yang didapat dari hasil

penelitian ini:

Penulis menyarankan agar tersedianya forum diskusi dalam Aplikasi e-learning ini. Sehingga dapat terjadi komunikasi yang interaktif baik antara guru dan siswa, dan siswa dengan siswa, Segera dibuatnya kebijakan yang mengijinkan proses belajar dan mengajar online sebagai suatu proses belajar formal serta dibuatnya prosedur dan aturan yang jelas dalam pelaksanaan belajar online, misalnya masalah kehadiran siswa dalam proses belajar dan mengajar, Security dari sistem lebih di tinggkatkan, maintenance harus lebih dijaga agar tidak terjadi kerusakan.

\section{Referensi}

Aditya, A. N. (2016). Jago PHP \& My SQL.
Jakarta: Laskar Grup (CEO).

Erma, D. (2014). Komputerisasi Akuntansi. Jakarta Selatan.

Kosasi, S. (2015). Perancangan E-Learning untuk Meningkatkan Motivasi Belajar Guru dan Siswa.

Biktra, R. (2015). Implementasi Sistem Informasi Pembelian Aksesoris Satpam Berbasis Web.

Prayitn. (2015). Indonesian Journal on Software Engineerin.

Hermawan. (2016). Kata Kunci: Sistem Informasi, Penjadwalan, Berbasis Web.

Pressman, R. (2015). Software Engineering, A Practitioner's. Approach Eighth Edition, New York: McGraw-Hill Education.

Dennis, A. (2015). System Analysis and Design with UML 5th Edition. United States of America: John Wiley and Sons.

Nixon, R. (2014). Learn PHP, MySQL, JavaScript, CSS \& HTML5 4th.United states of America: O'REILLY. 